\title{
An Entropy Model of Credit Risk Contagion in the CRT Market
}

\author{
Tingqiang Chen, ${ }^{1,2}$ Ying Chen, ${ }^{1}$ Xindan $\mathrm{Li}^{1}{ }^{1}$ and Jining Wang ${ }^{2}$ \\ ${ }^{1}$ School of Management and Engineering, Nanjing University, Nanjing 210093, China \\ ${ }^{2}$ School of Economics and Management, Nanjing Tech University, Nanjing 211816, China \\ Correspondence should be addressed to Ying Chen; cheny@nju.edu.cn
}

Received 22 October 2014; Revised 9 February 2015; Accepted 11 March 2015

Academic Editor: Seenith Sivasundaram

Copyright (C) 2015 Tingqiang Chen et al. This is an open access article distributed under the Creative Commons Attribution License, which permits unrestricted use, distribution, and reproduction in any medium, provided the original work is properly cited.

\begin{abstract}
This paper reports the effect of the change in the credit status of debtors on investors as a result of the banks' transferring of credit risk to investors in the credit risk transfer (CRT) market. Thus, an entropy spatial model is introduced, in which the spatial distance and nonlinear coupling between the banks and the investors, the transfer ability of credit risk of banks, and investor appetite for risk in the CRT network are considered. The contagion effects of the credit default of debtor on the default rates of investors in the CRT market are investigated using numerical simulation and sensitivity analysis.
\end{abstract}

\section{Introduction}

The recent subprime credit crisis motivates the development of models in which credit risk contagion has repercussions on other investors in the financial market, particularly the credit risk transfer (CRT) market. The effects of the credit risk contagion induced by the credit default of a debtor on the credit risk of investors in the CRT market are therefore evaluated.

Different approaches have been proposed to analyze the credit risk contagion. Davis and Lo $[1,2]$ introduced two classes of purely probabilistic models that explore the contagion effects of defaults in a portfolio of bonds. This portfolio provides a purely probabilistic alternative to Moody's diversity score analysis. Jarrow and $\mathrm{Yu}$ [3] generalized the existing reduced-form models to include default intensities dependent on the default of a counterparty. The counterparty includes the jump processes in the set of state variables, thereby capturing the interdependence among several default processes. Moreover, this study also provided examples with explicit bond pricing formulae and showed that marketwide risk factors and firm-specific counterparty risks interact to generate various shapes for the term structure of credit spreads. Frey and Backhaus [4] extended the approach of Jarrow and $\mathrm{Yu}$ [3] and assumed that the default intensity of a firm is directly affected by the default of other firms in the portfolio, which consider intensity-based dynamic models for dependent defaults. Focardi and Fabozzi [5] proposed a contagion model using percolation and random graphs. Giesecke [6] introduced credit contagion models on the basis of interacting particle systems and investigated the relative strength of cyclical correlations and contagion. Giesecke [7] also first attempted to integrate macroeconomic effects, causing cyclical default correlations, and contagion phenomena, associated with the local interaction of debtors with their business partners. Egloff et al. [8] proposed a simple model of credit contagion that includes macroeconomic and microstructural interdependencies among the debtors within a credit portfolio. Martin and Marrison [9] presented an approach to model credit contagion and the spread of credit events between related companies. Kchia and Larsson [10] provided a general framework that can handle arbitrarily numerous nonordered default times under the basic assumption that conditional joint densities exist. Their work clearly demonstrates the presence of informationdriven contagion effects.

A number of recent studies have considered the credit risk contagion of the CRT market. Haworth and Reisinger [11] proposed a numerical approach to modeling firm value dynamics and the default event, enabling the valuation of basket credit default swap spreads in a first passage framework with both asset correlation and default contagion. Their model could be used as a powerful tool for analyzing the spread impact of different dependence assumptions 
and parameter values. Allen and Carletti [12] proposed a model with banking and insurance sectors, which show that credit risk transfer can be beneficial because it improves risk sharing. However, credit risk transfer can also induce contagion and lead to a Pareto reduction in welfare. Haworth et al. [13] developed a two-dimensional structural framework for valuing credit default swaps and corporate bonds in the presence of default contagion. Jorion and Zhang [14] provided the first empirical analysis of credit contagion via direct counterparty effects and found that bankruptcy announcements cause negative abnormal equity returns and increases in CDS spreads for creditors. In addition, creditors with large exposures are more likely to suffer subsequently from financial distress. Chen and $\mathrm{He}$ [15] presented a network model of credit risk contagion that analyzes the mechanisms by which the degree of individual relationship, individual attitude to credit risk contagion, the individual ability to resist credit risk contagion, the monitoring strength of the financial market regulators, and the network structure affect credit risk contagion. Chen et al. [16, 17] proposed a series of nonlinear dynamics model of credit risk contagion in the CRT market to discuss the dynamic evolution behavior of credit risk contagion.

Entropy has been widely applied in the study of spatial interaction theory as the uncertainty measurement of the system to form the entropy spatial interaction theory. Entropy spatial interaction models can disperse the agents from an origin to all destinations, instead of assigning all agents to the nearest one. Moreover, entropy models can be obtained as an optimal solution of a mathematical programming problem such that the dispersion of the origin-destination flows is maximized by maximizing the entropy of the system [18]. Thus, entropy has become an effective tool to analyze the interaction flows between a set of origins and a set of destinations [19-21]. Such flows generally represent sets of agents that move from an origin to a destination zone [24]. Recently, the entropy spatial interaction theory has been applied in the economic and financial system to analyze the effect of the spatial location of economic subject and information flow on an economic system. Wilson [22] introduced a new framework for constructing spatial interaction and associated location models. The models contribute to multiregional demographic and input-output models, to transport and to location modeling, such as retail. Gordon [23] proposed an entropy spatial interaction model based on economic principles and random utility maximization. Barro and Basso [24] introduced an entropy spatial interaction model that considers the counterparty risk in a network of interdependent firms. This model describes the presence of business relations among different firms, which study the effects of credit contagion on the credit risk of a portfolio of bank loans. In an economic system, recent studies obtained entropy spatial model that mainly uses the effective information of the spatial distance matrix of the economic subjects in the economic networks and the weight distribution of network nodes to maximize entropy. However, studies on economic and financial systems have not considered the risk preference and heterogeneity of economic subjects as well as the heterogeneity of geographical location.
In this paper, several contributions to the study of credit risk contagion in the CRT network are reported. First, a new model of credit risk transfer is proposed, in which the spatial distance and the nonlinear coupling between banks and investors, the transfer ability of credit risk of banks, and investor appetite for risk in the CRT network are considered. This model mainly analyzes the liquidity ratios of credit risk through credit risk transfer from banks to investors. Second, a value contagion model of discrete time of a multiname credit derivative is built based on Basso and Barro [25], and then an entropy spatial contagion model of credit risk that consists of the above two models is obtained. Finally, a series of numerical simulation analysis of the proposed model is performed.

The paper is structured as follows. Entropy spatial models of credit risk transfer and contagion in the CRT network are discussed in Sections 2 and 3, respectively. In Section 4, the numerical simulation results from the proposed model are presented. Finally, Section 5 provides a summary with concluding remarks.

\section{Entropy Spatial Model of Credit Risk Transfer in the CRT Network}

2.1. Notations and Assumptions. A model of credit risk transfer is introduced. This model considers the spatial distance and the nonlinear coupling between the banks and investors, transfer ability of credit risk of the banks, and investor appetite for risk in the CRT network. Spatial transfer of credit risk is characterized by an entropy spatial interaction model. The CRT network is assumed to be a tiered structure network with multi-origin-destination (e.g., Figure 1); namely, a bank can transfer credit risk to multiple investors, and credit risk of an investor may come from multiple banks. Moreover, the credit risk transfer is unidirectional from banks to investors.

The notations used in this paper are summarized as follows:

(i) $I_{m}=\{1, \ldots, m\}$ refers to the set of banks in the CRT network and is also the set of origins of the CRT network;

(ii) $I_{n}=\{1, \ldots, n\}$ refers to the set of investors in the CRT network and is also the set of destinations of the CRT network;

(iii) $T_{i j}$, for $i \in I_{m}$ and $j \in I_{n}$, is the flow of credit derivatives from bank $i$ to investor $j$, generated by the model;

(iv) $O_{i}=\sum_{j=1}^{n} T_{i j}$, for $i \in I_{m}$, is the total flow of credit derivatives going out from bank $i$, observed in the CRT network;

(v) $H_{j}=\sum_{i=1}^{n} T_{i j}$, for $j \in I_{n}$, represents the total flow of credit derivatives coming into investor $j$, observed in the CRT network;

(vi) $T=\sum_{i=1}^{m} \sum_{j=1}^{n} T_{i j}=\sum_{i=1}^{m} O_{i}=\sum_{j=1}^{n} H_{j}$ is the total flow of credit derivatives observed in the CRT network; 


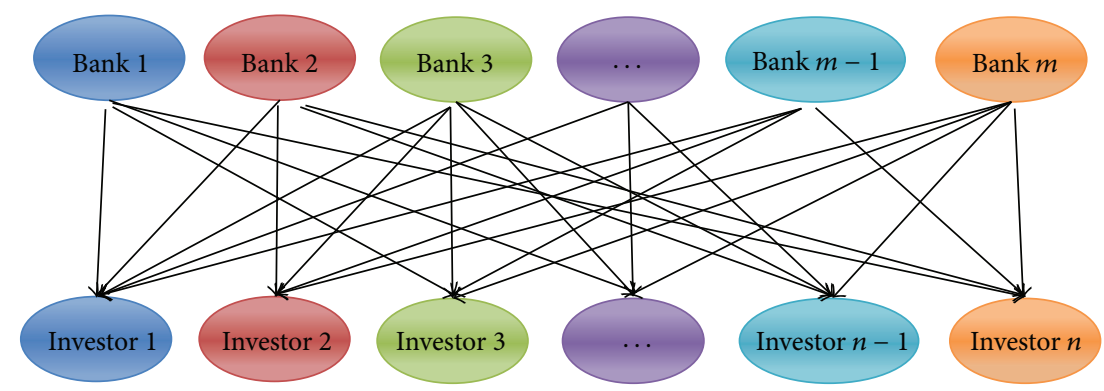

FIGURE 1: A tiered structure network of credit risk transfer with multi-origin-destination in CRT market.

(vii) $d_{i j}$, for $i \in I_{m}$ and $j \in I_{n}$, refers to the spatial distance between bank $i$ and investor $j$;

(viii) $r_{i j}=T_{i j} / T$, for $i \in I_{m}$ and $j \in I_{n}$, is the share of the total flow of credit derivatives which transfers from bank $i$ to investor $j$;

(ix) $o_{i}=O_{i} / T$, for $i \in I_{m}$, is the share of total flow of credit derivatives going out from bank $i$;

(x) $h_{j}=H_{j} / T$, for $j \in I_{n}$, is the share of total flow of credit derivatives coming into investor $j$;

(xi) $\eta_{i j}$, for $i \in I_{m}$ and $j \in I_{n}$, is the ability of bank $i$ to transfer credit derivatives that the level of credit risk exceed the average risk level to investor $j$;

(xii) $\beta_{j}$ represents the risk preference of investor $j$;

(xiii) $\mu_{i j}$, for $i \in I_{m}$ and $j \in I_{n}$, represents the nonlinear coupling coefficient between bank $i$ and investor $j$.

In addition, the locations of banks and investors are assumed to be homogeneous. This condition will reduce the complexity and difficulty of the present study and promote understanding the effect mechanism of the spatial distance between bank $i$ and investor $j$ on the credit risk contagion from bank $i$ to investor $j$.

2.2. Entropy Spatial Model of CRT. According to O'Kelly [21], Gordon [23], and Barro and Basso [24], an entropy spatial interaction model that is constrained both to banks and investors generates the bank-investor flows in the CRT network:

$$
T_{i j}=A_{i} B_{j} O_{i} H_{j} f\left(d_{i j}\right) \eta_{i j}^{\left(1-\beta_{j}\right)}
$$

where $A_{i}=\left[\sum_{j=1}^{n} B_{j} H_{j} f\left(d_{i j}\right)\right]^{-1}, B_{j}=\left[\sum_{i=1}^{m} A_{i} O_{i} f\left(d_{i j}\right)\right]^{-1}$, $i \in I_{m}, j \in I_{n}$, and the impedance function $f$ is a decreasing function of the spatial distance between bank $i$ and investor $j$ in the CRT network.

According to the above hypothesis and (1), the entropy spatial interaction model may be defined according to the shares of total flows $r_{i j}$ rather than on the flows $T_{i j}$ in the CRT network:

$$
r_{i j}=\frac{A_{i} B_{j} O_{i} H_{j} f\left(d_{i j}\right) \eta_{i j}{ }^{\left(1-\beta_{j}\right)}}{T} .
$$

That is,

$$
r_{i j}=a_{i} b_{j} o_{i} h_{j} f\left(d_{i j}\right) \eta_{i j}^{\left(1-\beta_{j}\right)}
$$

where $a_{i}=\left[\sum_{j=1}^{n} b_{j} h_{j} f\left(d_{i j}\right)\right]^{-1}$ and $b_{j}=\left[\sum_{i=1}^{m} a_{i} o_{i} f\left(d_{i j}\right)\right]^{-1}$, $i \in I_{m}, j \in I_{n}$.

For the impedance function $f$, O'Kelly [21], Gordon [23], and Barro and Basso [24] provided a wide and common definition in the entropy models as follows:

$$
f\left(d_{i j}\right)=e^{-\gamma d_{i j}}
$$

where $\gamma \in \mathbb{R}^{+}$is a real parameter.

Equation (4) is used to define the impedance function $f$ of credit risk transfer, which can maximize the entropy of the CRT network satisfying the given constraints and describe the effects of the spatial distance between bank $i$ and investor $j$ on credit risk transfer. However, in this definition, the nonlinear coupling between bank $i$ and investor $j$ during credit risk transfer is ignored. Several studies have reported on the role played by the nonlinear coupling in credit risk transfer, especially for evolution behavior to credit risk contagion (see, e.g., [16, 17]). Different levels of nonlinear coupling between banks and investors in the CRT market are found because of the existence of market noise and information asymmetry. The impedance function $f$ of credit risk transfer is redefined based on (4) to consider the effect of nonlinear coupling between banks and investors on credit risk transfer:

$$
f\left(\mu_{i j}, d_{i j}\right)=e^{-\mu_{i j} d_{i j}},
$$

where $\mu_{i j}$ is the nonlinear coupling coefficient of between bank $i$ and investor $j$ during credit risk transfer and $0<\mu_{i j} \leq$ 1.

Therefore, the new impedance function $f\left(\mu_{i j}, d_{i j}\right)$ can consider the effects of the spatial distance and the nonlinear coupling between bank $i$ and investor $j$ on credit risk transfer and can also maximize the entropy of the CRT network satisfying the given constraints. According to (3) and (5), the entropy spatial interaction model on the shares of total flows $r_{i j}$ can be written as follows:

$$
r_{i j}=a_{i} b_{j} o_{i} h_{j} e^{-\mu_{i j} d_{i j}} \eta_{i j}{ }^{\left(1-\beta_{j}\right)},
$$

where $a_{i}=\left[\sum_{j=1}^{n} b_{j} h_{j} f\left(d_{i j}\right)\right]^{-1}$ and $b_{j}=\left[\sum_{i=1}^{m} a_{i} o_{i} f\left(d_{i j}\right)\right]^{-1}$, $i \in I_{m}, j \in I_{n}$. 
The model defined using (6) may be useful, and $r_{i j}$ is the probability that a credit derivative in the CRT network will belong to the flow of credit derivatives moving from bank $i$ to investor $j$. Hence, the information on credit risk transfer from bank $i$ to investor $j$ can be very fully extracted and described through probability. The entropy spatial interaction model (6) is a doubly constrained model. Therefore, an entropy spatial model constrained only to either banks or investors can be defined. According to the needs of the present study, the entropy spatial model constrained only to investors is defined as follows:

$$
r_{i j}=b_{j} h_{j} e^{-\mu_{i j} d_{i j}} \eta_{i j}^{\left(1-\beta_{j}\right)}
$$

where $b_{j}=\left[\sum_{i=1}^{m} e^{-\mu_{i j} d_{i j}}\right]^{-1}, i \in I_{m}, j \in I_{n}$.

In the proposed model (7), the value of the entropy of the system of credit risk transfer is closely related with the spatial distance $d_{i j}$ and nonlinear coupling coefficient $\mu_{i j}$ between bank $i$ and investor $j$, the ability $\eta_{i j}$ of bank $i$ to transfer credit risk of exceeding the average risk level to investor $j$, and the risk preference $\beta_{j}$ of investor $j$ in the CRT market. Moreover, the effect of the risk preference $\beta_{j}$ of investor $j$ is significant on bank $i$ that transfers credit risk $[12,26]$.

\section{Entropy Spatial Model of Credit Risk Contagion in the CRT Network}

In the CRT market, banks optimize and reorganize credit risks that are formed by the debtors and then transfer them to investors through the form of credit derivatives. This behavior reduces the financing cost and risk concentration, satisfies the regulatory capital requirements, and maximizes the banks' own interests. If the credit status of the debtors changes or the debtors credit defaults, the value of credit derivatives that are associated with the debtors fluctuates and affects banks and investors. Moreover, when the loss rate caused by the fluctuation of the value of credit derivatives is greater than the given threshold value $\theta$, banks and investors will have similar credit default behavior. This condition will result in the contagion effect of credit risk.

In this paper, the effects of the credit status of the debtors on investors of the CRT market are primarily discussed. To describe the contagion effect of credit risk, a value contagion model of discrete time based on the discrete time is introduced on the basis of the discrete time model proposed by Basso and Barro [25], which models the asset value of a multiname credit derivatives following a structural approach. In particular, the value of a multiname credit derivative is described by the sum of the microeconomic component which introduces a contagion effect caused by past distresses and a random disturbance term of the external environment. The microeconomic component mainly measures the financial distress of banks by observing the past default of the debtors included in the credit derivatives. The financial distress measure $M_{i}(t)$ of bank $i$ at time $t$ is assumed to originate from the debtors included in the credit derivatives, compared with the average default rate $p(t)$ observed in the economy at time $t$. Thus the financial distress measure $M_{i}(t)$ can be described by the following equation:

$$
M_{i}(t)=p(t)-\left[\sum_{k \in \psi_{i}(t)} \zeta_{k}(t) w_{i k}(t)+p(t) m_{i}(t)\right]
$$

where $\psi_{i}(t)$ denotes the set of the major debtors included in the credit derivatives, $w_{i k}(t)$ denotes the important degree of the debtors $k$ included in the credit derivatives, and $w_{i k}(t)=($ the value of credit assets of the debtors $k$ )/(the value of the credit derivatives $s), w_{i k}(t)>\theta$. This condition implies that the loss rate caused by the change in the credit status of the debtors may be greater than the given threshold value $\theta$. Moreover, when the debtors $k$ present serious credit event, such as credit default or bankruptcy, the loss rate can be greater than the given threshold value $\theta$. $m_{i}(t)=1-\sum_{k \in \psi_{i}(t)} w_{i k}(t)$ denotes the important degree of all minor debtors included in the credit derivatives. Moreover, the credit default of each minor debtor that leads to the fluctuation of the value of credit derivatives is far less than the given threshold value $\theta$. That is, the credit defaults of single minor debtor cannot cause the financial distress of banks. $\zeta_{k}(t)$ is an indicator function that the major debtors $k$ included in the credit derivatives present credit defaults at time $t$, and $\zeta_{k}(t)$ is defined as

$$
\zeta_{k}(t)= \begin{cases}1 & \begin{array}{l}
\text { if the major debtors } k \text { included in the credit } \\
\text { derivatives emerge credit defaults at time } t
\end{array} \\
0 & \text { others. }\end{cases}
$$

Only the credit defaults of the major debtors are considered in (9). According to Basso and Barro [25], the percentage of minor debtors equal to the average default rate $p(t)$ of the economy is assumed to credit default.

The effect of the past credit defaults of the debtors included in the credit derivatives is interred to long-term memory characteristic on the current credit risk of banks, and the effect of long-term memory is assumed to present an exponential decay in time as an influence of the past credit default $[24,25]$. The time of past credit defaults of the debtors included in the credit derivatives is $\tau$, with $\tau>1$. Thus, the effect factor of the past credit defaults of the debtors included in the credit derivatives on the current financial distress of banks is $\lambda_{s(i)}$, with $0 \leq \lambda_{s(i)}<1$. The overall financial distress $P_{i}(t)$ of bank $i$ at time $t$ is measured as the sum of the effects of all the past credit defaults of its debtors as follows:

$$
P_{i}(t)=\sum_{\tau=1}^{\infty} \lambda_{s(i)}^{\tau} M_{i}(t-\tau)
$$


That is,

$$
\begin{aligned}
P_{i}(t)=\sum_{\tau=1}^{\infty} \lambda_{s(i)}^{\tau}[p(t-\tau) & {\left[\sum_{k \in \psi_{i}(t-\tau)} \zeta_{k}(t-\tau) w_{i k}(t-\tau)\right.} \\
& \left.-\left[p(t-\tau) m_{i}(t-\tau)\right]\right] .
\end{aligned}
$$

Equation (11) depicts the contagion effect of the past credit default of the debtors included in the credit derivatives on the current financial distress of bank $i$. According to Basso and Barro $[24,25]$, if the value of $\lambda_{s(i)}$ is sufficiently small, only the term $\sum_{\tau=1}^{\infty} \lambda_{s(i)}^{\tau} p(t-\tau)$ is not negligible in the practical application. Therefore, in order to achieve its own capital safety and improve operation efficiency of bank $i$, bank $i$ can moderately transfer credit risk caused by the debtors to investors of the CRT market. Thus the change in the credit status of the debtors included in the credit derivatives has contagion effect on investors because of the role of credit risk transfer in the CRT market. Through simultaneous equations (7) and (11), the entropy spatial model of credit risk contagion in the CRT market can be obtained as follows:

$$
\pi_{i j}=r_{i j} P_{i}(t)+\varepsilon_{i}(t)
$$

That is,

$$
\begin{aligned}
& \pi_{i j}=\frac{\sum_{i=1}^{m} T_{i j}}{\sum_{i=1}^{m} \sum_{j=1}^{n} T_{i j}} \frac{e^{-\mu_{i j} d_{i j}}}{\sum_{i=1}^{m} e^{-\mu_{i j} d_{i j}}} \eta_{i j}{ }^{\left(1-\beta_{j}\right)} \\
& \cdot \sum_{\tau=1}^{\infty} \lambda_{s(i)}^{\tau}[p(t-\tau) \\
& -\left[\sum_{k \in \psi_{i}(t-\tau)} \zeta_{k}(t-\tau) w_{i k}(t-\tau)\right. \\
& \left.\left.+p(t-\tau) m_{i}(t-\tau)\right]\right]+\varepsilon_{i}(t)
\end{aligned}
$$

where $\pi_{i j}$ is the measurement of credit risk contagion between bank $i$ and investor $j$, which is mainly caused by bank $i$ transferring credit risk to investor $j ; i \in I_{m} ; j \in I_{n}$. $\varepsilon_{i}(t)$ denotes the random disturbance term of external environment. Moreover, $\varepsilon_{i}(t)$ is assumed to be a normal distribution with zero mean and standard deviation $\sigma_{\varepsilon_{s(i)}}$. This parameter denotes the effect of the change in external environment on credit risk contagion in the CRT market, including macroeconomic environment, financial environment, industry environment, and legal environment. According to (13), the entropy spatial model of credit risk contagion can maximize the entropy of credit risk contagion in the CRT network that satisfies the given constraints and can depict the effects of the spatial distance and nonlinear coupling between banks and investors. The model also presents the ability of banks to transfer credit risk, the appetite for risk of investors, the credit status of the debtors, and external environment on credit risk contagion of the CRT network.

\section{Simulation Analysis of Credit Risk Contagion}

In the absence of a large number of time series data of an empirical test, numerical simulation analysis is the most effective testing method. Thus, numerical simulation analysis that considers the different values of the parameters in the entropy spatial model is performed. The credit derivatives that are mainly constituted by the credit loans of mediumsized and small enterprises are considered. Let the number of banks $m=1000$, and the number of investors $n=300$ in the CRT network. In addition, the average credit default rate in the economy $p=0.06$, the effect factor of the past credit defaults of the debtors $\lambda_{s}=0.15$, and the disturbance degree of external environment $\sigma=0.4$. Moreover, we assumed the number of the credit derivatives of the flow in the CRT market is inferred to be equal to 10000, and the number of bank $i$ owning credit derivatives is assumed to be a normal distribution, with a mean of 20 and the standard deviation of 4 . The ratio of the number of major debtors and minor debtors is assumed to be equal to 0.25 . Thus, the effects of the spatial distance $d_{i j}$ and nonlinear coupling $\mu_{i j}$ between banks and investors, ability of credit risk transfer of banks $\eta_{i j}$, concentration of credit risk of investor $h_{j}$, and appetite for risk of investors $\beta_{j}$ on credit risk contagion of the CRT network through numerical simulation are discussed under the aforementioned given values of the parameters.

In Figure 2, credit risk contagion showed significant spatial distance effect in the CRT network. The contagion effect of credit risk present an exponential decay in the spatial distance between banks and investors in the CRT network. The larger the spatial distance between banks and investors, the smaller the effect of credit risk contagion in the CRT network. This phenomenon is primarily due to the fact that the information asymmetry and trade cost significantly increase with the increase in the spatial distance between banks and investors. This condition will lead to reduced willingness of investors to invest and probability of credit risk transfer from banks to investors in the long distances. In Figures 2 and 3, we find that the default rate gradually increases with the increase in the concentration of credit risk of investor $h_{j}$, the ability of credit risk transfer of banks $\eta_{i j}$, and the appetite for risk of investors $\beta_{j}$. Moreover, the effect of the ability of banks $\eta_{i j}$ to transfer credit risk on credit risk contagion have marginal diminishing effect. However, the default rate gradually decreases with the increase in nonlinear coupling $\mu_{i j}$ between banks and investors. Comparative results from Figures 2 and 3 show that Figure 3 is more intuitive to understand and analyze the effect of $h_{j}, \eta_{i j}, \mu_{i j}$, and 

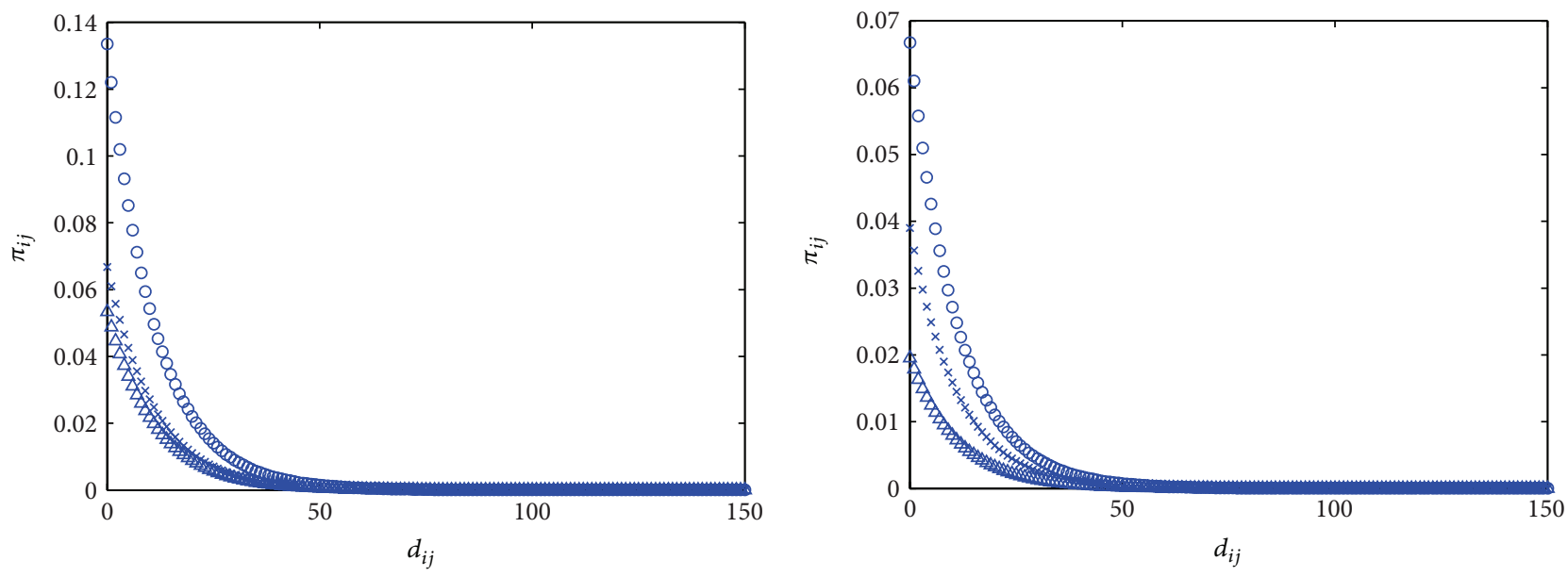
$\triangle h_{j}=0.08 ; \mu_{i j}=0.09 ; \eta_{i j}=0.6 ; \beta_{j}=0.7$
$\times h_{j}=0.1 ; \mu_{i j}=0.09 ; \eta_{i j}=0.6 ; \beta_{j}=0.7$
$\circ h_{j}=0.2 ; \mu_{i j}=0.09 ; \eta_{i j}=0.6 ; \beta_{j}=0.7$

(a)

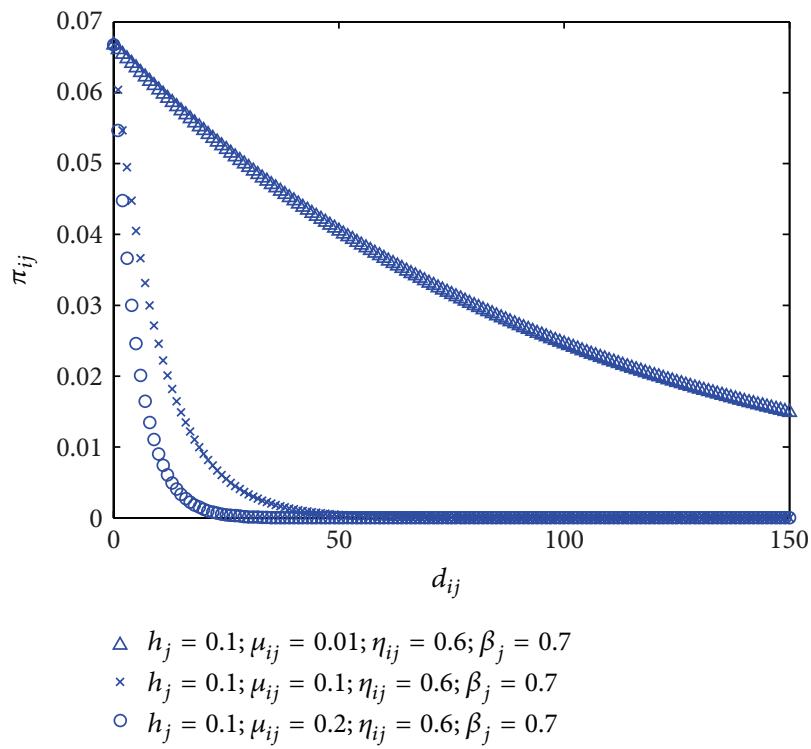

(c)

$$
\begin{aligned}
\triangle h_{j} & =0.1 ; \mu_{i j}=0.09 ; \eta_{i j}=0.01 ; \beta_{j}=0.7 \\
\times h_{j} & =0.1 ; \mu_{i j}=0.09 ; \eta_{i j}=0.1 ; \beta_{j}=0.7 \\
\triangle h_{j} & =0.1 ; \mu_{i j}=0.09 ; \eta_{i j}=0.6 ; \beta_{j}=0.7
\end{aligned}
$$

(b)

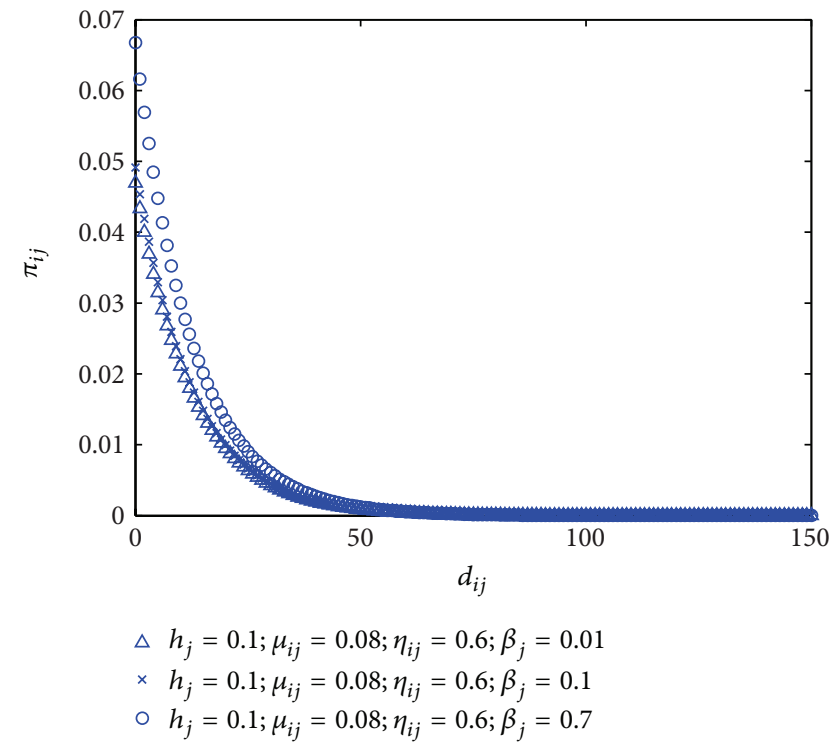

(d)

FIGURE 2: Effect of spatial distance on credit risk contagion in the CRT network with different values of $h_{j}, \mu_{i j}, \eta_{i j}$, and $\beta_{j}$.

$\beta_{j}$ on credit risk contagion in the CRT network than Figure 2. In addition, the credit risk contagion presents inhibitory effect of correlation between banks and investors in the CRT network. The correlation between banks and investors shows inhibitory effect on the credit default behavior of investors. In fact, the inhibitory effect is short-term and unstable. In the actual financial market, the appetite for risk of investors contributes to credit risk transfer of banks. However, the risk appetite can also intensify the contagion effect of credit risk and increase instability of the financial system.

\section{Conclusion}

In this paper, an entropy spatial model of credit risk contagion that considers the effect of the change in the credit status of the debtors on investors as a result of the transfer of credit risk by banks to investor in the CRT market. The effects of the spatial distance and nonlinear coupling between banks and investors, ability of bank to credit risk transfer credit risk, concentration of credit risk of investor, and appetite for risk of investors on credit risk contagion are discussed. Moreover, we found that credit risk contagion exhibits significant spatial distance effect and inhibitory effect on the correlation between banks and investors in the CRT network through numerical simulations and the sensitivity analysis.

However, the present studies may also be applied in other areas such as the inhomogeneity of the different geographical areas, banks, and investors and the interactivity of credit risk contagion. 


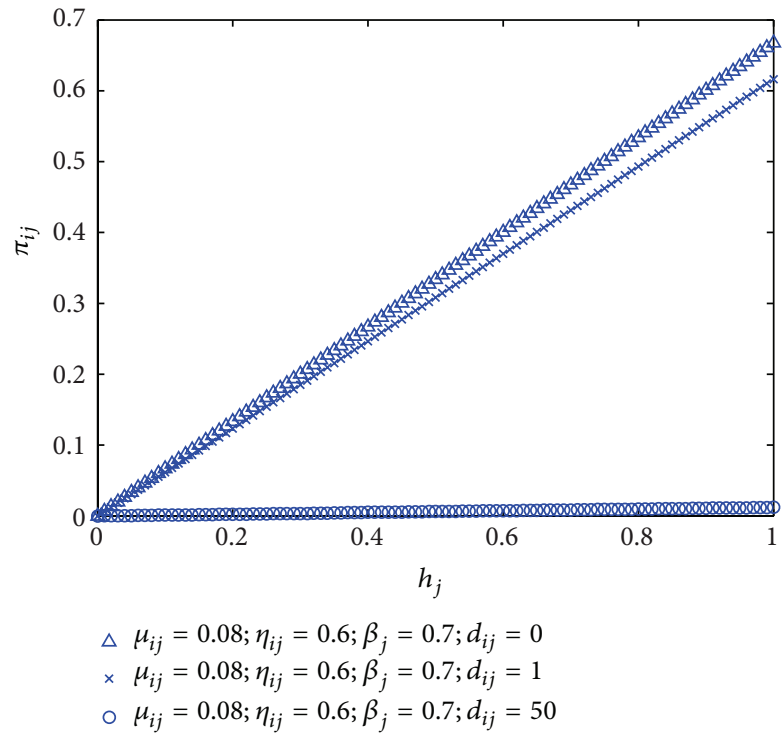

(a)

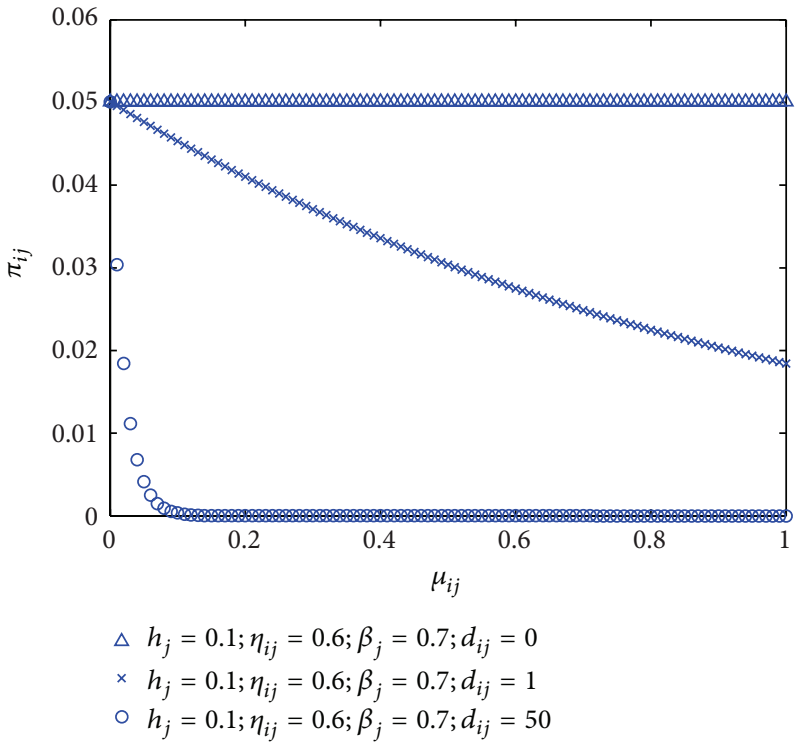

(c)

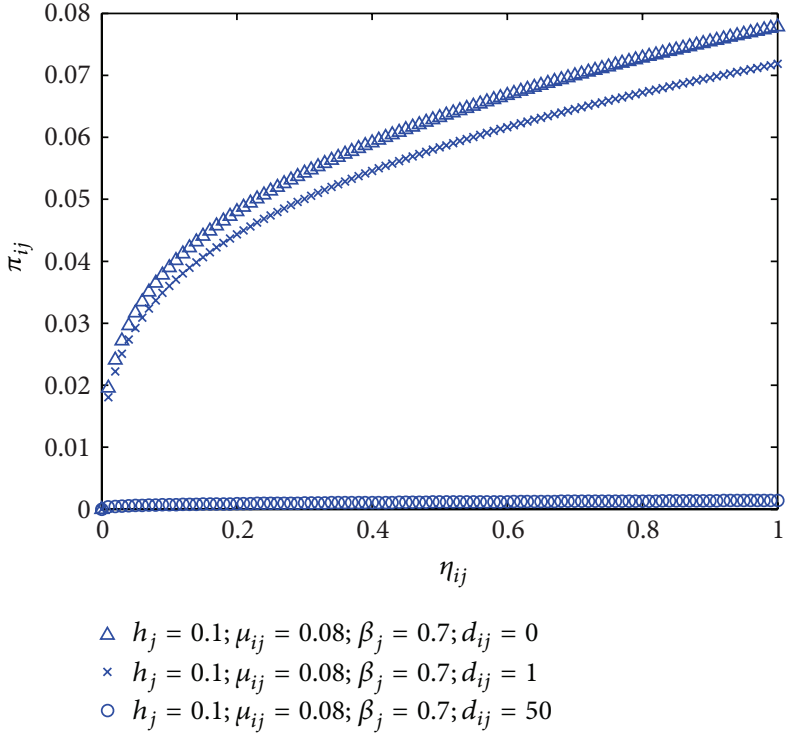

(b)

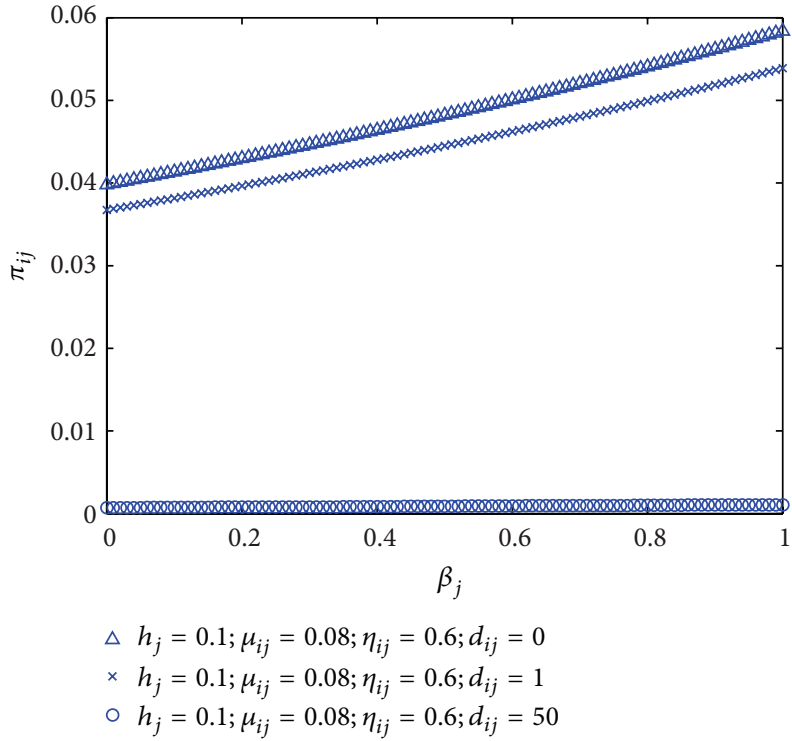

(d)

FIGURE 3: Effect of the concentration of credit risk of investor $h_{j}$, the ability of credit risk transfer of banks $\eta_{i j}$, nonlinear coupling $\mu_{i j}$ between banks and investors, and the appetite for risk of investors $\beta_{j}$ on credit risk contagion in the CRT network.

\section{Conflict of Interests}

There is no conflict of interests regarding the publication of this paper.

\section{Acknowledgments}

The authors wish to express their gratitude to the referees for their invaluable comments. This work was supported by the National Natural Science Foundation of China (nos.
70932003 and 71301078), China Postdoctoral Science Foundation (2014M561626), and the Philosophy and Social Sciences Research Funded Projects in Colleges and Universities of Jiangsu (2014SJB081).

\section{References}

[1] M. Davis and V. Lo, Modelling Default Correlation in Bond Portfolios, Imperial College, London, UK, 2000.

[2] M. Davis and V. Lo, "Infectious defaults," Quantitive Finance, vol. 1, pp. 382-387, 2001. 
[3] R. A. Jarrow and F. Yu, "Counterparty risk and the pricing of defaultable securities," Journal of Finance, vol. 56, no. 5, pp. 1765-1799, 2001.

[4] R. Frey and J. Backhaus, Interacting Defaults and Counterparty Risk: A Markovian Approach, Department of Mathematics, University of Leipzig, Leipzig, Germany, 2003.

[5] S. M. Focardi and F. J. Fabozzi, "A percolation approach to modeling credit risk loss distribution under contagion," Journal of Risk, vol. 7, pp. 75-94, 2004.

[6] K. Giesecke, "Correlated default with incomplete information," Journal of Banking and Finance, vol. 28, no. 7, pp. 1521-1545, 2004.

[7] K. Giesecke, "Default and information," Journal of Economic Dynamics and Control, vol. 30, no. 11, pp. 2281-2303, 2006.

[8] D. Egloff, M. Leippold, and P. Vanini, "A simple model of credit contagion," Journal of Banking \& Finance, vol. 31, no. 8, pp. 2475-2492, 2007.

[9] D. Martin and C. Marrison, “Credit risk contagion," Risk, vol. 4, pp. 90-94, 2007.

[10] Y. Kchia and M. Larsson, "Credit contagion and risk management with multiple non-ordered defaults," Working Paper, Ecole Polytechnique and Cornell University, 2011.

[11] H. Haworth and C. Reisinger, "Modeling basket credit default swaps with default contagion," Working Paper, University of Oxford, Oxford, UK, 2006.

[12] F. Allen and E. Carletti, "Credit risk transfer and contagion," Journal of Monetary Economics, vol. 53, no. 1, pp. 89-111, 2006.

[13] H. Haworth, C. Reisinger, and W. Shaw, "Modelling bonds and credit default swaps using a structural model with contagion," Quantitative Finance, vol. 8, no. 7, pp. 669-680, 2008.

[14] P. Jorion and G. Zhang, "Credit contagion from counterparty risk," The Journal of Finance, vol. 64, no. 5, pp. 2053-2087, 2009.

[15] T. Q. Chen and J. M. He, "A network model of credit risk contagion," Discrete Dynamics in Nature and Society, vol. 2012, Article ID 513982, 13 pages, 2012.

[16] T. Q. Chen, J. M. He, and J. N. Wang, "Bifurcation and chaotic behavior of credit risk contagion based on Fitzhugh-Nagumo system," International Journal of Bifurcation and Chaos, vol. 23, no. 7, Article ID 1350117, 2013.

[17] T. Q. Chen and J. M. He, "Dynamics evolution of credit risk contagion in the CRT market," Discrete Dynamics in Nature and Society, vol. 2013, Article ID 206201, 9 pages, 2013.

[18] A. G. Wilson, Entropy in Urban and Regional Modelling, Pion Limited, London, UK, 1970.

[19] G. Clarke, R. Langley, and W. Cardwell, "Empirical applications of dynamic spatial interaction models," Computers, Environment and Urban Systems, vol. 22, no. 2, pp. 157-184, 1998.

[20] H. M. Celik and J.-M. Guldmann, "Spatial interaction modeling of interregional commodity flows," Socio-Economic Planning Sciences, vol. 41, no. 2, pp. 147-162, 2007.

[21] M. E. O’Kelly, "Entropy-based spatial interaction models for trip distribution," Geographical Analysis, vol. 42, no. 4, pp. 472-487, 2010.

[22] A. Wilson, "Entropy in urban and regional modelling: retrospect and prospect," Geographical Analysis, vol. 42, no. 4, pp. 364-394, 2010.

[23] I. Gordon, "Entropy, variety, economics, and spatial interaction," Geographical Analysis, vol. 42, no. 4, pp. 446-471, 2010.

[24] D. Barro and A. Basso, "Credit contagion in a network of firms with spatial interaction," European Journal of Operational Research, vol. 205, no. 2, pp. 459-468, 2010.
[25] A. Basso and D. Barro, "Counterparty risk: a credit contagion model for a bank loan portfolio," The ICFAI Journal of Financial Risk Management, vol. 2, pp. 1-24, 2005.

[26] T. Santos, "Comment on: credit risk transfer and contagion," Journal of Monetary Economics, vol. 53, no. 1, pp. 113-121, 2006. 


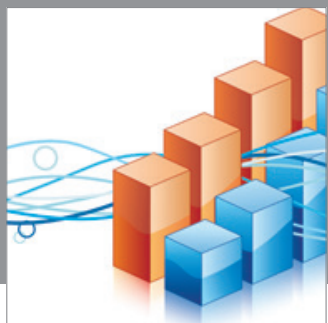

Advances in

Operations Research

mansans

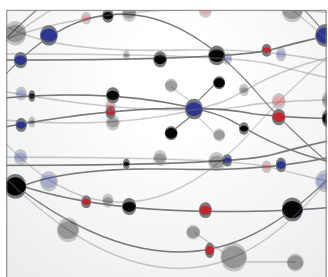

The Scientific World Journal
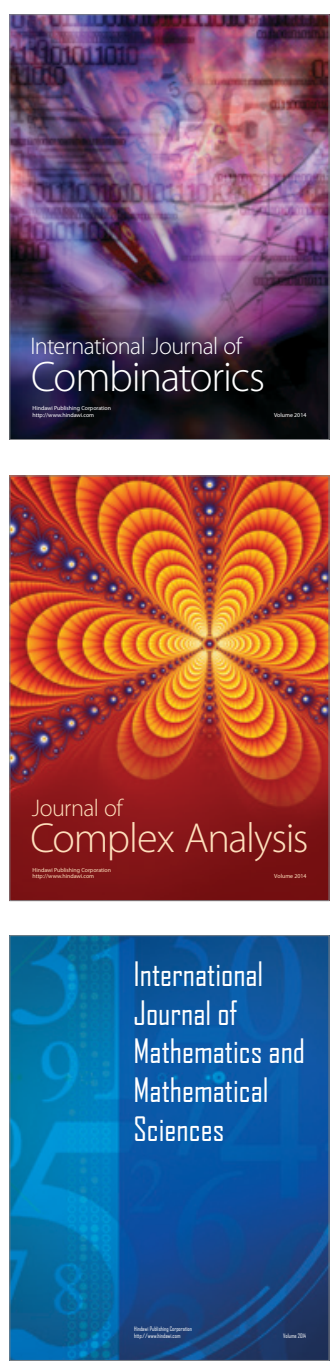
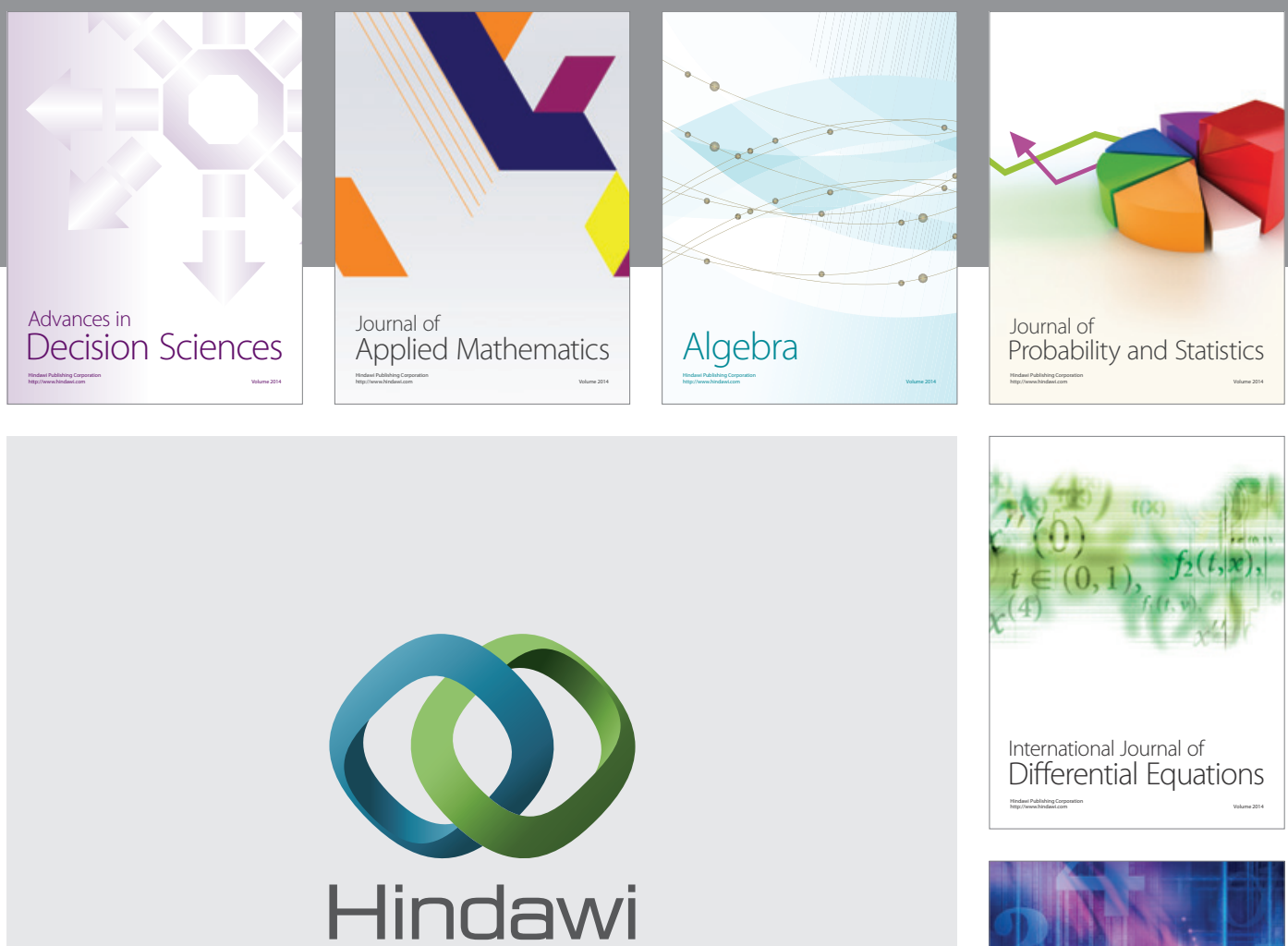

Submit your manuscripts at http://www.hindawi.com
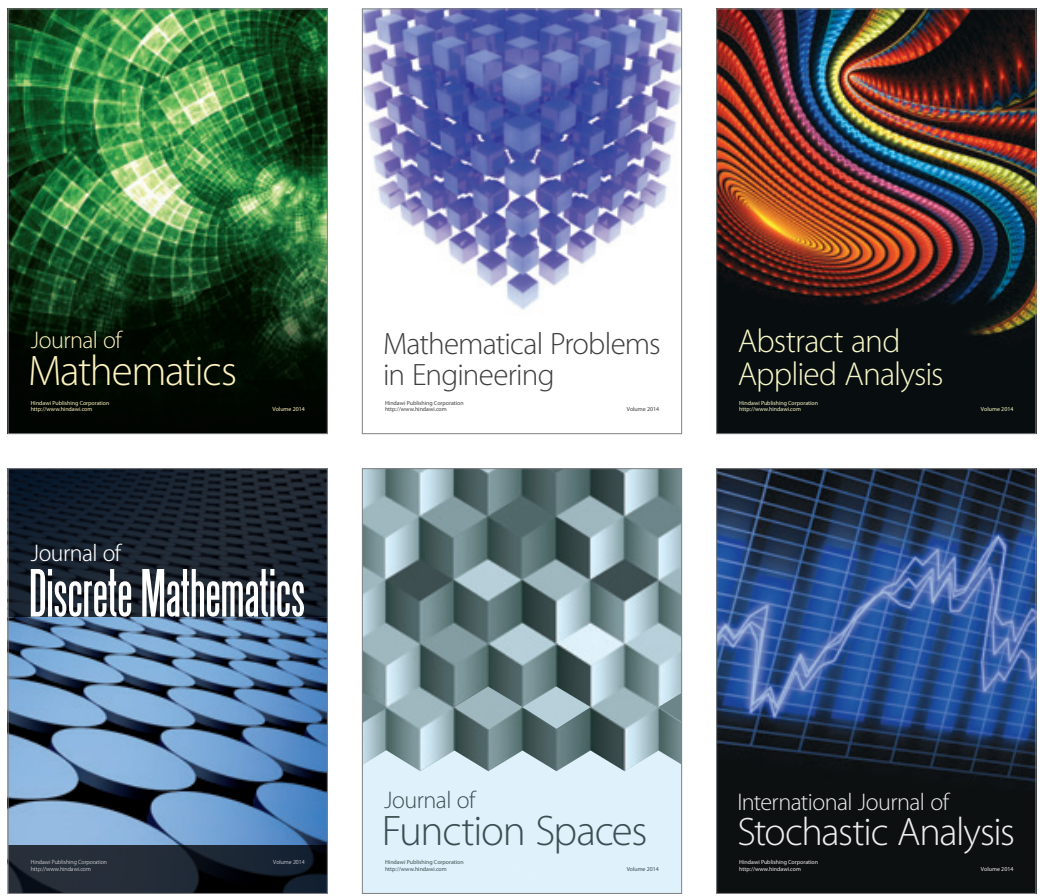

Journal of

Function Spaces

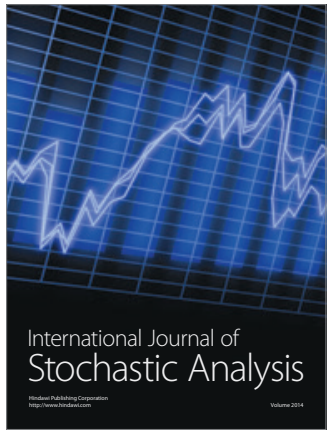

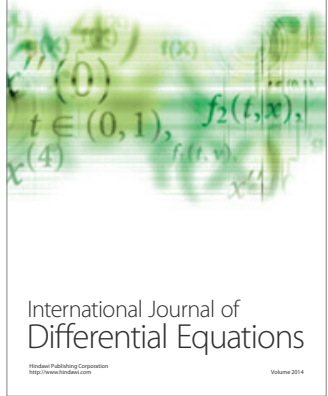
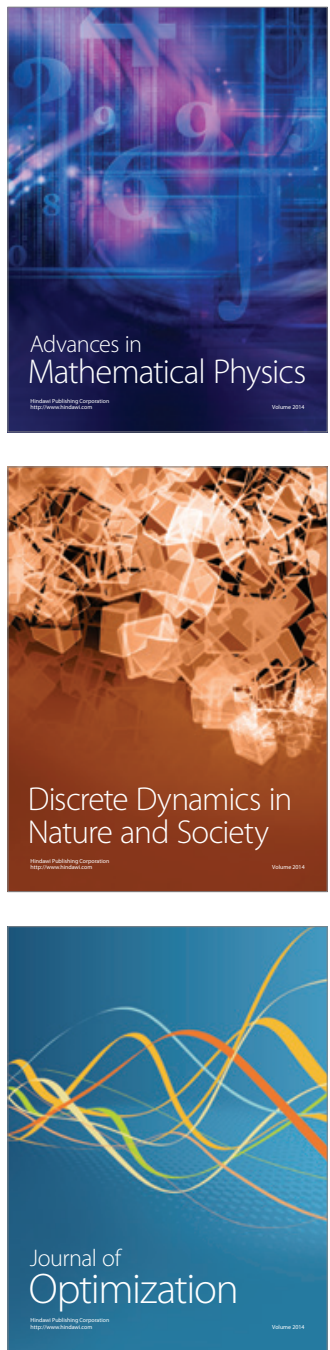